\title{
Infirmity and Injury Complexity are Risk Factors for Surgical-site Infection after Operative Fracture Care
}

\author{
Abdo Bachoura MD, Thierry G. Guitton MSc, \\ R. Malcolm Smith MD, Mark S. Vrahas MD, \\ David Zurakowski PhD, David Ring MD, PhD
}

Received: 6 July 2010/ Accepted: 29 November 2010/Published online: 16 December 2010

(c) The Author(s) 2010. This article is published with open access at Springerlink.com

\begin{abstract}
Background Orthopaedic surgical-site infections prolong hospital stays, double rehospitalization rates, and increase healthcare costs. Additionally, patients with orthopaedic surgical-site infections (SSI) have substantially greater physical limitations and reductions in their health-related quality of life. However, the risk factors for SSI after operative fracture care are unclear.

Questions/purpose We determined the incidence and quantified modifiable and nonmodifiable risk factors for SSIs in patients with orthopaedic trauma undergoing surgery.
\end{abstract}

Each author certifies that he or she has no commercial associations (eg, consultancies, stock ownership, equity interest, patent/licensing arrangements, etc) that might pose a conflict of interest in connection with the submitted article.

Each author certifies that his or her institution approved or waived approval for the human protocol for this investigation and that all investigations were conducted in conformity with ethical principles of research. This is an Institutional Review Board (IRB) approved study.

A. Bachoura, T. G. Guitton, D. Ring

Orthopaedic Hand and Upper Extremity Service, Massachusetts

General Hospital, Harvard Medical School, Boston, MA, USA

R. M. Smith, M. S. Vrahas

Department of Orthopaedics, Massachusetts General Hospital, Harvard Medical School, Boston, MA, USA

D. Zurakowski

Departments of Anesthesia and Surgery, Children's Hospital

Boston, Harvard Medical School, Boston, MA, USA

D. Ring $(\square)$

Massachusetts General Hospital, Yawkey Center, Suite 2100,

55 Fruit Street, Boston, MA 02114, USA

e-mail: dring@partners.org
Patients and Methods We retrospectively indentified, from our prospective trauma database and billing records, 1611 patients who underwent 1783 trauma-related procedures between 2006 and 2008. Medical records were reviewed and demographics, surgery-specific data, and whether the patients had an SSI were recorded. We determined which if any variables predicted SSI.

Results Six factors independently predicted SSI: (1) the use of a drain, OR 2.3, 95\% CI (1.3-3.8); (2) number of operations OR 3.4, 95\% CI (2.0-6.0); (3) diabetes, OR 2.1, 95\% CI (1.2-3.8); (4) congestive heart failure (CHF), OR 2.8, 95\% CI (1.3-6.5); (5) site of injury tibial shaft/plateau, OR 2.3, 95\% CI (1.3-4.2); and (6) site of injury, elbow, OR $2.2,95 \%$ CI (1.1-4.7).

Conclusion The risk factors for SSIs after skeletal trauma are most strongly determined by nonmodifiable factors: patient infirmity (diabetes and heart failure) and injury complexity (site of injury, number of operations, use of a drain).

Level of Evidence Level II, prognostic study. See the Guideline for Authors for a complete description of levels of evidence.

\section{Introduction}

It is estimated that SSIs occur in approximately 500,000 of the approximately 27 million $(2.8 \%)$ operations performed annually in the United States [4, 17]. SSIs represent as much as $1 / 3$ of all nosocomial infections $[11,15]$, and are the most common nosocomial infection (38\%) in surgical patients [21]. Orthopaedic SSIs prolong total hospital stays by a median of 2 weeks per patient, approximately double rehospitalization rates, and increase healthcare costs by greater than $300 \%$ [45]. Additionally, patients with 
orthopaedic SSIs have substantially greater physical limitations and reductions in their health-related quality of life [45].

Several studies have assessed factors associated with SSI in joint arthroplasty [2, 7, 16, 22, 28-30, 33, 34, 37, 38, $41,46]$ and spine surgery $[3,5,26,35,36]$, but there are relatively little data regarding SSI risk in orthopaedic fracture care. Patients who undergo surgery for skeletal trauma have a relatively high rate of SSIs [3, 16, 37, 42], most likely related to injury to the soft tissue envelope, contamination, and other factors.

The main objectives of the study are to: (1) determine the incidence of SSIs in patients with orthopaedic trauma and place these findings in the context of other orthopaedic literature; (2) determine whether modifiable risk factors (hair removal and technique, type of skin preparation, attending surgeon, use of a wound drain, use of wound packing, type of fixation, temporary use of external fixation before definitive surgery, number of preoperative stay days), and nonmodifiable risk factors (gender, age, site of injury, side of injury, wound classification, polytrauma and associated injuries, diabetic status, presence of CHF, American Society of Anesthesiologists [ASA] score, infection at another site preoperatively or postoperatively, and total number of operations at the same site during admission) are associated with the development of SSIs in patients with orthopaedic trauma; and (3) quantify the contribution of independent risk factors to the probability of the development of an SSI. An improved knowledge of the modifiable and nonmodifiable risk factors will help counsel patients and might contribute to improved practice.

\section{Patients and Methods}

Using billing records and a prospective trauma database, we retrospectively identified all 2562 patients who underwent surgical procedures for skeletal trauma between January 1, 2006 and October 9, 2008. Patients were included if they were older than 18 years and had a patient medical record with at least 30 days followup after the date of surgery. We excluded 951 patients for the following reasons: (1) those who did not have at least one followup recorded within 3 months of surgery; (2) patients with burn injury and no fracture; (3) those who had implant removal only; (4) patients who had initial trauma surgery at an outside hospital or patients who presented with SSIs after being treated at another hospital; (5) metastatic fractures; (6) death within 30 days of initial surgery; and (7) patients with back, spine, hand, and finger injuries. Patients with spine fractures were excluded as trauma orthopaedists rarely perform spine surgery and there is an abundance of literature regarding SSI after spine surgery. Hand and finger injuries were excluded as their treatment falls under the realm of hand, rather than trauma, surgery. These exclusions left 1611 patients who underwent 1783 traumarelated procedures. One hundred seventy-two patients (9.6\%) had surgery at more than one site, and each site was considered separately: 134 patients $(7.5 \%)$ had two sites, $29(1.6 \%)$ had three sites, and nine $(0.5 \%)$ had four sites. The duration of patient followup was not recorded. No patients were recalled specifically for this study; all data were obtained from medical records and radiographs. IRB approval was obtained.

Medical records were reviewed retrospectively by an investigator $(\mathrm{AB})$ not involved in the patients' care. The following were recorded: gender, age, ASA score, presence of SSI, number of preoperative stay days, wound classification, injury site, side of injury, temporary use of external fixation before definitive surgery, polytrauma, associated injury, hair removal (yes/no and technique), the solution used to clean and prepare the skin, attending surgeon, use of a drain, use of wound packing, type of fixation, diabetic status, CHF, infection at another site preoperatively or postoperatively, and total number of operations at the same site during admission.

Patients were classified according to the ASA score [1] as follows: (1) normal healthy patient, (2) patient with mild systemic disease, (3) patient with severe systemic disease (4) patient with severe systemic disease that is a constant threat to life, (5) moribund patient who is not expected to survive without the operation, (6) a patient declared braindead whose organs are being removed for donor purposes. One thousand three hundred-sixty-eight cases were classified by the anesthesia staff at the time of surgery, the remaining 415 were classified by an investigator $(\mathrm{AB})$ using the operative report and discharge summaries as the scores were not readily available in the anesthesia database.

SSI was defined according to the Centers for Disease Control and Prevention (CDC) criteria [21]. The CDC classifies SSI as either incisional or organ/space. Incisional SSIs were divided into those involving only skin and subcutaneous tissue (superficial incisional SSI), and those involving deeper soft tissues of the incision (deep incisional SSI). Any SSI category can be diagnosed on a clinical or laboratory basis (wound culture). Superficial, deep, and organ/space SSIs can develop within 30 days of surgery when there is no implant or foreign material in place. When an implant is left in place, deep incisional and organ/space infections can develop within 1 year of surgery. We applied the CDC definition of SSI using data from the medical record, but ultimately did not use the classification of infection types, because we are not convinced that it is reliable in the arm and leg. We made no attempt to distinguish superficial from deep infections. 
Pin-site infections that developed while using an external fixation device were not classified as SSIs so as to adhere to the CDC definition of an SSI, but also because they did not require a hospital admission or surgery and therefore would not be considered a major complication in our department.

Polytrauma was defined as trauma to more than one among the musculoskeletal, abdominal, cardiothoracic, urogenital, vascular, and central nervous systems. Multiple isolated orthopaedic injuries were not classified as polytrauma unless they were associated with hemodynamic instability. Associated injuries were subdivided into associated head injury, associated chest injury, associated abdominal injury, and associated urogenital injury. Associated head injuries were defined as traumatic head injuries resulting in a brain contusion, intracranial bleeding, such as epidural, subdural, and subarachnoid hematomas, or a diffuse axonal injury. Associated chest injuries were defined as a lung contusion, a pneumothorax, or a hemothorax. Rib fractures with no intrathoracic disorders were not listed as chest injuries. Each associated injury was investigated separately to determine if it was associated with the development of SSI.

The number of operations was defined as the number of surgeries for one site of trauma. For patients who had more than one operation at a specific site, the last surgery was the reference surgery for this investigation (unless it was removal of an external fixator).

The sites of injury were defined as: hip (intertrochanteric, peritrochanteric, subtrochanteric, femoral neck); femur (femoral shaft and distal femur); tibia shaft; ankle (malleolar and talar); foot; patella; shoulder and clavicle (proximal humerus, humeral head, and glenoid); elbow (including proximal forearm and distal humerus fractures); forearm; wrist (distal radius, distal ulna, and carpal bones); soft tissue; acetabulum, sacrum, and pelvis; arm; tibial plateau; and pilon.

Type of fixation was classified as open reduction and internal fixation, external fixation, prosthetic joint, percutaneous pinning, and none. A prosthetic joint included total hip arthroplasty or hip hemiarthroplasty, shoulder arthroplasty, total elbow arthroplasty, radial head prosthesis, and total knee arthroplasty or knee hemiarthroplasty.

Wounds were classified as clean, clean contaminated, contaminated, or dirty [9, 31]. Wound classification was obtained from the nursing operative record. However, at times the accuracy of the nursing data was questioned and the investigator independently categorized wound classifications for 154 of the 1783 procedures using the description of the wound as mentioned in the operative report. Hair removal was classified as no hair removed, razor used, or clippers used. The solution used to prepare the skin for surgery was defined as soap, followed by alcohol, followed by Betadine $^{\circledR}$ (Purdue Pharma, Stamford, CT, USA) (the traditional skin preparation at our hospital), or others. A vacuum dressing (VAC) was counted as a wound packing and drain. Drains used included a VAC dressing (KCI USA, Inc, San Antonio, TX, USA) in 17 surgeries, a Hemovac (Zimmer, Dover, OH, USA) in 225, a JP (Cardinal Health, McGaw Park, IL, USA) drain in six, a Blake (Ethicon Inc, Somerville, NJ, USA) in five, and a Penrose (Deroyal Surgical- Rose Hill, Rose Hill, VA, USA) in five. No drain was used in 1525 surgeries. Among the surgeries with wound packing, a VAC dressing was used in 20, and other wound packing was used in six.

Bivariable and multivariable logistic regression modeling was used to determine the independent predictors of SSI, using the likelihood ratio test to assess significance and a generalized estimating equations (GEE) approach to account for multiple fractures or surgeries for the same patient (1783 procedures, 1611 patients) [12]. Given the overall incidence of SSI (75 of 1783, 4.2\%), 13 variables were tested by multivariable analysis [18] to achieve a prediction algorithm with reliable odds ratios and confidence intervals for measuring infection risk [44]. Based on the final multivariable model, we derived predicted probabilities of SSI according to the final set of independent risk factors. Multivariable logistic regression models were constructed using backward stepwise variable selection with a $\mathrm{p}$ value less than 0.05 as the criterion for variable retention, and a forward selection procedure also was conducted to assess internal validity of the fitted model. The models' fit was evaluated by the Hosmer-Lemeshow goodness-of-fit statistic with a larger $\mathrm{p}$ value indicating better fit and reliability, and predictive accuracy of the multivariable model was assessed by the c-index [18]. We did not test all two-way interactions in the multivariable analysis as there were no expected interactions based on a priori clinical grounds and did not believe the statistical power was sufficient for testing potentially complex twoway interaction terms in the model. Two-tailed values of $\mathrm{p}<0.05$ were considered significant. Tibial shaft/plateau fractures were combined in the multivariable analysis owing to the anatomic proximity and to have a sufficient number of entries to perform the analysis.

\section{Results}

There were 75 of 1783 cases of infections, an incidence of $4.2 \%$.

We found an association between SSI and the following modifiable risk factors: the use of a wound drain ( $p<0.001)$, use of a VAC dressing $(p<0.001)$, and temporary external fixation $(\mathrm{p}<0.001)$ (Table 1$)$. We also found an association between SSI and the following nonmodifiable risk factors: wound classification $(p<0.001)$, 
Table 1. Modifiable risk factors associated with SSI

\begin{tabular}{|c|c|c|c|}
\hline Variable & $\begin{array}{l}\text { SSI } \\
(N=75)\end{array}$ & $\begin{array}{l}\text { No SSI } \\
(\mathrm{N}=1708)\end{array}$ & $\mathrm{p}$ Value \\
\hline Hair removal & & & 0.20 \\
\hline No hair removed & $66(4.1)$ & $1546(95.9)$ & \\
\hline Razor & $2(13.3)$ & $13(86.7)$ & \\
\hline Clippers & $7(4.5)$ & $149(95.5)$ & \\
\hline Preparation solution & & & 0.50 \\
\hline Triple preparation & $62(4.1)$ & $1463(95.9)$ & \\
\hline Others & $13(5.0)$ & $245(95.0)$ & \\
\hline Use of a drain & & & $<0.001$ \\
\hline No & $50(3.3)$ & $1469(96.7)$ & \\
\hline Yes & $25(9.5)$ & $239(90.5)$ & \\
\hline Wound packing & & & 0.11 \\
\hline No & $3(10.7)$ & $25(89.3)$ & \\
\hline Yes & $72(4.1)$ & $1683(95.9)$ & \\
\hline Definitive fixation & & & 0.21 \\
\hline ORIF & $61(4.1)$ & $1416(95.9)$ & \\
\hline External fixation & $1(7.7)$ & $12(92.3)$ & \\
\hline Prosthetic joint & $9(7.5)$ & $99(92.5)$ & \\
\hline Percutaneous pinning & $0(0.0)$ & $58(100.0)$ & \\
\hline None & $5(3.9)$ & $123(96.1)$ & \\
\hline Temporary external fixation & & & $<0.001$ \\
\hline No & $64(3.7)$ & $1645(96.3)$ & \\
\hline Yes & $11(14.9)$ & $63(85.1)$ & \\
\hline Surgeon & & & 0.37 \\
\hline A & $31(5.4)$ & 544 (94.6) & \\
\hline B & $10(3.9)$ & $246(96.1)$ & \\
\hline $\mathrm{C}$ & $5(2.3)$ & $216(97.7)$ & \\
\hline $\mathrm{D}$ & $10(4.0)$ & $237(96.0)$ & \\
\hline Others & $19(3.9)$ & $465(96.1)$ & \\
\hline Preoperative stay, (days) & & & 0.14 \\
\hline Median (range) & $2(0-12)$ & $1(0-30)$ & \\
\hline
\end{tabular}

Data are number with percentages given in parentheses, unless otherwise indicated. SSI - surgical-site infection, ORIF-open reduction internal fixation.

ASA classification $(\mathrm{p}=0.014)$, number of operations $(\mathrm{p}<0.001)$, CHF $(\mathrm{p}=0.006)$, and diabetes $(\mathrm{p}=0.007)$ (Table 2). Additionally, three specific surgical sites were more likely $(\mathrm{p}=0.001)$ to be infected than other sites: SSI occurred in eight of 121 elbow fractures (6.6\%); five of 66 tibial plateau fractures (7.6\%); and 13 of 149 tibial shaft fractures (8.7\%) (Table 3). Twenty-six of 149 tibial shaft fractures were open injuries, and SSIs developed in six of these injuries. Five of 66 tibial plateau fractures were open injuries, and a SSI developed in one of these injuries. Sixteen of 121 elbow fractures were open injuries, and SSIs developed in four of these 16 elbow fractures.

We identified six factors that independently predicted SSI: (1) the use of a drain (OR 2.3, p = 0.004); (2) number
Table 2. Nonmodifiable risk factors associated with SSI

\begin{tabular}{|c|c|c|c|}
\hline Variable & $\begin{array}{l}\text { SSI } \\
(\mathrm{N}=75)\end{array}$ & $\begin{array}{l}\text { No SSI } \\
(\mathrm{N}=1708)\end{array}$ & $\mathrm{p}$ Value \\
\hline Gender & & & 0.56 \\
\hline Female & $35(3.9)$ & $865(96.1)$ & \\
\hline Male & $40(4.5)$ & $843(95.5)$ & \\
\hline Age at surgery (years) & & & 0.069 \\
\hline Median (range) & $54(19-93)$ & $52(18-98)$ & \\
\hline Side of injury & & & 0.39 \\
\hline Right & $44(4.8)$ & $864(95.2)$ & \\
\hline Left & $30(3.5)$ & $821(96.5)$ & \\
\hline Midline & $1(4.2)$ & $23(95.8)$ & \\
\hline Wound classification & & & $<0.001$ \\
\hline 1 & $51(3.3)$ & $1472(96.7)$ & \\
\hline 2 & $4(9.1)$ & $40(90.9)$ & \\
\hline 3 & $18(9.6)$ & $169(90.4)$ & \\
\hline 4 & $2(6.9)$ & $27(93.1)$ & \\
\hline ASA classification & & & 0.014 \\
\hline 1 & $22(4.2)$ & $501(95.8)$ & \\
\hline 2 & $24(2.9)$ & $808(97.1)$ & \\
\hline 3 & $26(6.8)$ & $359(93.2)$ & \\
\hline 4 & $3(7.0)$ & $40(93.0)$ & \\
\hline Polytrauma & & & 0.66 \\
\hline No & $68(4.1)$ & $1573(95.9)$ & \\
\hline Yes & $7(4.9)$ & $135(95.1)$ & \\
\hline \multicolumn{4}{|l|}{ Associated injuries } \\
\hline Head & $2(3.0)$ & $64(97.0)$ & 0.99 \\
\hline Chest & 7 (8.6) & $74(91.4)$ & 0.08 \\
\hline Abdominal & $5(8.1)$ & $57(91.9)$ & 0.18 \\
\hline Urogenital & $0(0.0)$ & $15(100.0)$ & 0.99 \\
\hline Number of operations & & & $<0.001$ \\
\hline 1 & $53(3.3)$ & $1565(96.7)$ & \\
\hline 2 or more & $22(13.3)$ & $143(86.7)$ & \\
\hline $\mathrm{CHF}$ & & & 0.006 \\
\hline No & $67(3.9)$ & $1647(96.1)$ & \\
\hline Yes & $8(11.6)$ & $81(88.4)$ & \\
\hline Diabetes & & & 0.007 \\
\hline No & $59(3.7)$ & $1529(96.3)$ & \\
\hline Yes & $16(8.2)$ & $179(91.8)$ & \\
\hline \multicolumn{4}{|l|}{ Infection at other site } \\
\hline Preoperatively & $1(1.7)$ & $59(98.3)$ & 0.51 \\
\hline Postoperatively & $3(3.1)$ & 93 (96.9) & 0.79 \\
\hline
\end{tabular}

Data are number with percentages given in parentheses, unless otherwise indicated.

SSI—surgical site infection, $\mathrm{CHF}$ - congestive heart failure, ASAAmerican Society of Anesthesiology.

of operations (OR 3.4, p < 0.001); (3) diabetes (OR 2.1, $\mathrm{p}=0.03$ ); (4) CHF (OR 2.8, p = 0.03); (5) site of injurytibial shaft/plateau (OR 2.3, p = 0.005); and (6) site of injury-elbow (OR 2.2, p = 0.01) (Table 4). Except for 
the use of a drain, all of these independent risk factors are nonmodifiable. To further quantify the risk of SSI, predicted probabilities for SSI were determined using the derived independent risk factors. The risk of a SSI increased with increasing numbers of risk factors and this

Table 3. Incidence of infection according to site*

\begin{tabular}{lcc}
\hline Site of injury & $\begin{array}{c}\text { Number of } \\
\text { procedures }\end{array}$ & $\begin{array}{l}\text { Number } \\
\text { infected (\%) }\end{array}$ \\
\hline Hip & 300 & $16(5.3)$ \\
Femur & 129 & $4(3.1)$ \\
Tibia shaft & 149 & $13(8.7)$ \\
Ankle/fibula & 291 & $9(3.1)$ \\
Foot & 64 & $3(4.7)$ \\
Patella & 45 & $2(4.4)$ \\
Shoulder/clavicle & 73 & $2(2.7)$ \\
Elbow & 121 & $8(6.6)$ \\
Forearm & 32 & $1(3.1)$ \\
Wrist & 289 & $3(1.0)$ \\
Soft tissue & 66 & $3(4.5)$ \\
Acetabulum, sacrum, pelvis & 83 & $4(4.8)$ \\
Arm & 43 & $0(0.0)$ \\
Tibial plateau & 66 & $5(7.6)$ \\
Pilon & 32 & $2(6.2)$ \\
Total & 1783 & $75(4.2)$ \\
\hline
\end{tabular}

* Pearson chi square test indicated significant overall differences between sites; additional testing revealed significantly higher rates for tibial shaft, tibial plateau, and elbow $(\mathrm{p}=0.001)$. was distinct for elbow fractures (Table 5; Fig. 1), tibia fractures (Table 6; Fig. 2), and other sides (Table 7; Fig. 3). The multivariable predictive model of SSI was reliable (Hosmer-Lemeshow statistic, $\mathrm{p}=0.62$ ) and accurate (c-index $=0.81$ ). Backward and forward selection yielded identical results, including the same six of the 13 candidate variables tested: wound drain, number of operations, CHF, diabetes, tibial shaft/tibial plateau injury site, and elbow injury site. Among the 13 variables examined, age $(\mathrm{p}=0.20)$, preoperative stay $(\mathrm{p}=0.73)$, wound classification $(\mathrm{p}=0.12), \quad$ ASA classification $(p=0.13)$, use of external fixation $(p=0.18)$, associated chest injury $(p=0.13)$, and wound packing $(p=0.89)$ were not retained as predictors of infection in the final multivariable logistic regression model.

Table 4. Significant predictors of SSI *

\begin{tabular}{llc}
\hline Variable & \multicolumn{2}{l}{ Multivariable logistic regression model } \\
\cline { 2 - 3 } & $\begin{array}{l}\text { Adjusted odds } \\
\text { ratio (95\% CI) }\end{array}$ & $\mathrm{p}$ Value \\
\hline Wound drain & $2.3(1.3-3.8)$ & 0.004 \\
Number of operations & $3.4(2.0-6.0)$ & $<0.001$ \\
Congestive heart failure & $2.8(1.3-6.5)$ & 0.026 \\
Diabetes & $2.1(1.2-3.8)$ & 0.028 \\
Site of injury & & 0.010 \\
Tibial shaft/plateau & $2.3(1.3-4.2)$ & 0.005 \\
Elbow & $2.2(1.1-4.7)$ & 0.011 \\
\hline
\end{tabular}

$* \mathrm{~N}=1611$ patients, 1783 procedures; $\mathrm{CI}=$ confidence interval.

Table 5. Multivariable algorithm for predicting SSI for tibial shaft or plateau injuries and a comparison with the observed results

\begin{tabular}{|c|c|c|c|c|c|c|}
\hline $\begin{array}{l}\text { Number } \\
\text { of surgeries }\end{array}$ & Wound drain & $\mathrm{CHF}$ & Diabetes & $\begin{array}{l}\text { Observed proportion } \\
\text { of SSI }\end{array}$ & $\begin{array}{l}\text { Predicted } \\
\text { probability (\%) }\end{array}$ & $\begin{array}{l}95 \% \text { confidence } \\
\text { interval }\end{array}$ \\
\hline 1 & no & no & no & $6 / 134(4.5 \%)$ & 4.5 & $2.5-7.7$ \\
\hline 1 & no & no & yes & $1 / 14(7.1 \%)$ & 8.8 & $4.2-17.6$ \\
\hline 1 & yes & no & no & $5 / 32(15.6 \%)$ & 9.5 & $5.0-17.5$ \\
\hline 1 & no & yes & no & none & 11.6 & $4.5-26.8$ \\
\hline 1 & yes & no & yes & none & 18.0 & $8.3-34.6$ \\
\hline 1 & no & yes & yes & $0 / 1(0 \%)$ & 21.4 & $9.6-41.1$ \\
\hline 1 & yes & yes & no & $1 / 1(100 \%)$ & 22.9 & $8.6-48.4$ \\
\hline 1 & yes & yes & yes & none & 38.1 & $17.3-64.4$ \\
\hline 2 or more & no & no & no & $2 / 13(15.4 \%)$ & 13.8 & $7.7-23.6$ \\
\hline 2 or more & no & no & yes & $0 / 3(0 \%)$ & 25.0 & $12.5-43.7$ \\
\hline 2 or more & yes & no & no & $3 / 15(20 \%)$ & 26.6 & $15.8-41.3$ \\
\hline 2 or more & no & yes & no & $0 / 1(0 \%)$ & 31.1 & $13.4-56.8$ \\
\hline 2 or more & yes & no & yes & $0 / 1(0 \%)$ & 43.0 & $24.2-64.0$ \\
\hline 2 or more & no & yes & yes & none & 48.4 & $25.9-71.6$ \\
\hline 2 or more & yes & yes & no & none & 50.5 & $24.8-75.9$ \\
\hline 2 or more & yes & yes & yes & none & 67.9 & $42.3-85.9$ \\
\hline
\end{tabular}

$\mathrm{SSI}=$ surgical site infection, $\mathrm{CHF}=$ congestive heart failure. 


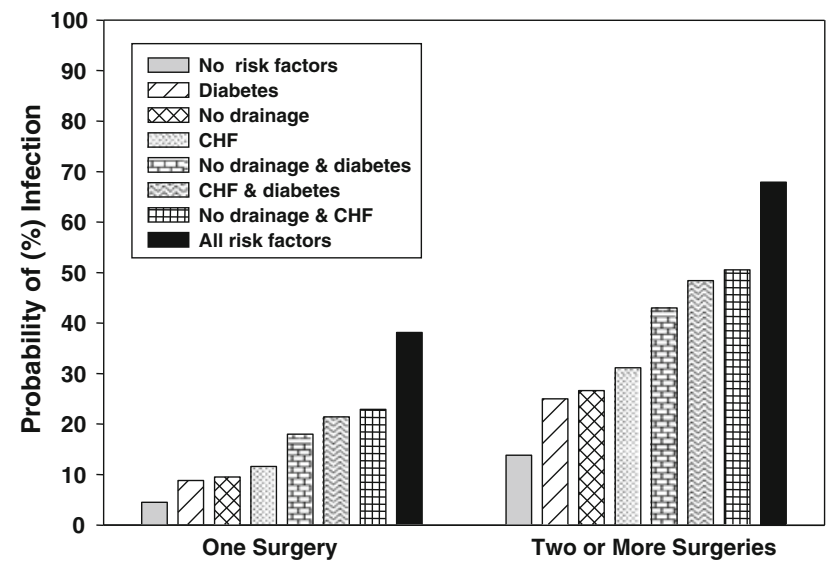

Fig. 1 The graph shows the probability of SSI for patients with tibial shaft fractures or tibial plateau injuries stratified by the number of surgeries and based on risk factors including wound drainage versus no drainage, $\mathrm{CHF}$, and diabetes. Risk increases with increasing number of risk factors and is greater with more than one operation. Probabilities were derived from the multivariable logistic regression analysis.

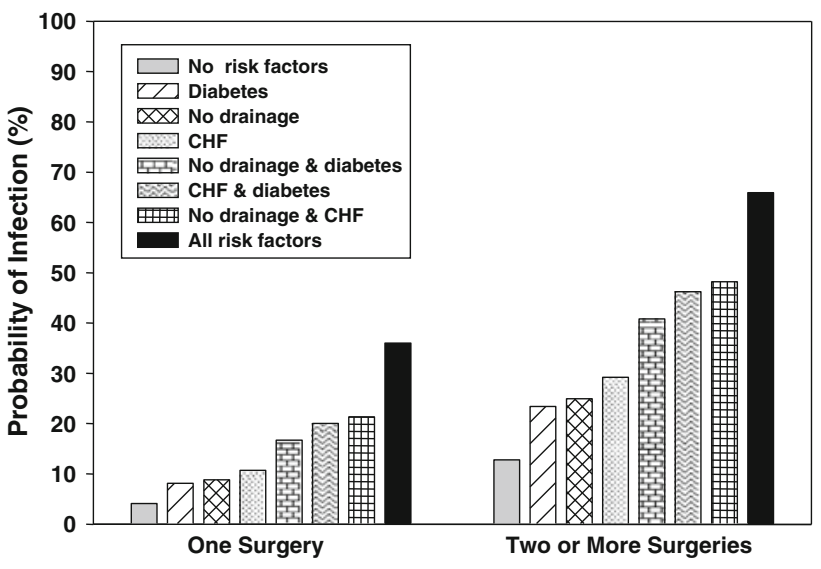

Fig. 2 The graph shows the probability of SSI for patients with elbow injuries stratified by the number of surgeries and based on risk factors including wound drainage versus no drainage, $\mathrm{CHF}$, and diabetes. Risk increases with increasing number of risk factors and is greater with more than one operation. Probabilities were derived from multivariable logistic regression analysis.

Table 6. Multivariable algorithm for predicting SSI for elbow injuries and a comparison with the observed results

\begin{tabular}{|c|c|c|c|c|c|c|}
\hline $\begin{array}{l}\text { Number } \\
\text { of surgeries }\end{array}$ & $\begin{array}{l}\text { Wound } \\
\text { drain }\end{array}$ & $\mathrm{CHF}$ & Diabetes & $\begin{array}{l}\text { Observed proportion } \\
\text { of SSI }\end{array}$ & $\begin{array}{l}\text { Predicted } \\
\text { probability (\%) }\end{array}$ & $\begin{array}{l}95 \% \text { confidence } \\
\text { interval }\end{array}$ \\
\hline 1 & no & no & no & $5 / 85(5.9 \%)$ & 4.1 & $1.9-8.5$ \\
\hline 1 & no & no & yes & $0 / 7(0 \%)$ & 8.1 & $3.4-18.3$ \\
\hline 1 & yes & no & no & $0 / 11(0 \%)$ & 8.8 & $3.9-18.6$ \\
\hline 1 & no & yes & no & $0 / 2(0 \%)$ & 10.7 & $3.7-27.5$ \\
\hline 1 & yes & no & yes & none & 16.7 & $6.8-35.4$ \\
\hline 1 & no & yes & yes & $1 / 2(50 \%)$ & 20.0 & $7.9-42.0$ \\
\hline 1 & yes & yes & no & none & 21.3 & $7.1-48.9$ \\
\hline 1 & yes & yes & yes & none & 36.0 & $14.6-64.9$ \\
\hline 2 or more & no & no & no & $1 / 9(11.1 \%)$ & 12.8 & $5.8-25.9$ \\
\hline 2 or more & no & no & yes & $0 / 2(0 \%)$ & 23.4 & $10.0-45.7$ \\
\hline 2 or more & yes & no & no & $0 / 2(0 \%)$ & 24.9 & $12.2-44.2$ \\
\hline 2 or more & no & yes & no & none & 29.2 & $10.9-58.3$ \\
\hline 2 or more & yes & no & yes & none & 40.8 & $19.8-65.7$ \\
\hline 2 or more & no & yes & yes & $1 / 1(100 \%)$ & 46.2 & $21.5-72.9$ \\
\hline 2 or more & yes & yes & no & none & 48.2 & $20.7-76.9$ \\
\hline 2 or more & yes & yes & yes & none & 65.9 & $36.7-86.6$ \\
\hline
\end{tabular}

SSI = surgical-site infection, $\mathrm{CHF}=$ congestive heart failure.

\section{Discussion}

SSIs are one of the most common major complications in patients with skeletal trauma. Patients with orthopaedic trauma typically have soft tissue injury, which distinguishes them from patients undergoing elective arthroplasty or spine surgery. This study aimed to (1) determine the incidence of SSI among patients with orthopaedic trauma; (2) determine which modifiable and nonmodifiable risk factors were associated with the development of SSIs in patients with orthopaedic trauma; and (3) quantify the contribution of independent risk factors to the probability of an SSI developing.

Our study is subject to some limitations. First, we relied on the electronic medical record. Relying on the electronic medical record made the study much easier to do, but resulted in the exclusion of many factors that may be associated with SSI development such as severity of injury, 
Table 7. Multivariable algorithm for predicting SSI for other sites* and a comparison with the observed results

\begin{tabular}{|c|c|c|c|c|c|c|}
\hline $\begin{array}{l}\text { Number } \\
\text { of surgeries }\end{array}$ & Wound drain & $\mathrm{CHF}$ & Diabetes & $\begin{array}{l}\text { Observed proportion } \\
\text { of SSI }\end{array}$ & $\begin{array}{l}\text { Predicted } \\
\text { probability (\%) }\end{array}$ & $\begin{array}{l}95 \% \text { confidence } \\
\text { interval }\end{array}$ \\
\hline 1 & no & no & no & $19 / 1017(1.9 \%)$ & 2.0 & $1.4-2.8$ \\
\hline 1 & no & no & yes & $6 / 104(5.8 \%)$ & 4.0 & $2.1-7.5$ \\
\hline 1 & yes & no & no & $3 / 132(2.3 \%)$ & 4.3 & $2.7-6.9$ \\
\hline 1 & no & yes & no & $1 / 24(4.2 \%)$ & 5.3 & $2.4-11.6$ \\
\hline 1 & yes & no & yes & $2 / 19(10.5 \%)$ & 8.6 & $4.2-16.6$ \\
\hline 1 & no & yes & yes & $1 / 24(4.5 \%)$ & 10.4 & $5.1-20.0$ \\
\hline 1 & yes & yes & no & $1 / 4(25 \%)$ & 11.2 & $4.6-25.1$ \\
\hline 1 & yes & yes & yes & $1 / 5(20 \%)$ & 20.8 & $9.6-39.5$ \\
\hline 2 or more & no & no & no & $5 / 70(7.1 \%)$ & 6.4 & $3.6-11.2$ \\
\hline 2 or more & no & no & yes & $2 / 5(20 \%)$ & 12.5 & $5.8-24.8$ \\
\hline 2 or more & yes & no & no & $4 / 31(12.9 \%)$ & 13.4 & $8.0-21.7$ \\
\hline 2 or more & no & yes & no & $0 / 1(0 \%)$ & 16.2 & $6.8-33.9$ \\
\hline 2 or more & yes & no & yes & $2 / 7(28.6 \%)$ & 24.3 & $12.4-42.3$ \\
\hline 2 or more & no & yes & yes & $0 / 1(0 \%)$ & 28.6 & $13.9-50.0$ \\
\hline 2 or more & yes & yes & no & $2 / 3(66.7 \%)$ & 30.4 & $13.5-54.8$ \\
\hline 2 or more & yes & yes & yes & none & 47.5 & $25.6-70.5$ \\
\hline
\end{tabular}

SSI $=$ surgical-site infection, $\mathrm{CHF}=$ congestive heart failure. $*$ Other sites include injuries other than tibial shaft/plateau or elbow.

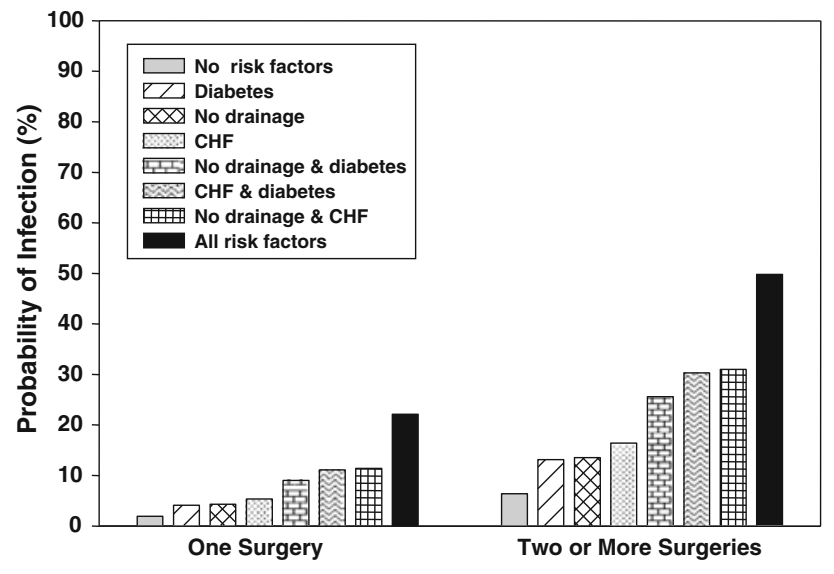

Fig. 3 The graph shows the probability of SSI for patients with injuries other than tibial shaft/plateau or elbow stratified by the number of surgeries and based on risk factors including wound drainage versus no drainage, $\mathrm{CHF}$, and diabetes. Risk increases with increasing number of risk factors and is greater with more than one operation. Probabilities were derived from multivariable logistic regression analysis.

nutritional status, precise timing of preoperative antibiotics, obesity, smoking, alcohol use, and intraoperative blood transfusion. Second, we made the assumption that a patient who was not diagnosed with an infection within 30 days and did not return specifically for treatment of an infection within the next 12 months did not have an infection. Therefore we may have missed a few patients who were diagnosed with infection between 1 and 12 months elsewhere. Given that the majority of orthopaedic SSIs are diagnosed within the first month [37] and most patients would have returned to see us if they had an infection, we are confident that insisting on 1 year of followup for all patients would not affect the results of our study. Third, missing ASA data were classified by an investigator in 415 of 1783 cases based on the medical records. We believe this is adequate as the ASA classification, although simple and useful, has limited reliability among anesthesiologists [27]. Fourth, our method of considering temporary external fixation and serial debridement not as separate individual fracture surgeries, but rather as potential risk factors and part of a staged treatment approach may not be consistent with all studies that assess SSI rates in operative fracture care. Fifth, the reliability and accuracy of SSI classification has been questioned, but the sensitivity of the various surveillance methods reported in the literature varies between $80 \%$ and $90 \%$, and the specificity is near $100 \%$ $[21,40]$.

We found a $4.2 \%$ incidence of SSIs after surgery for skeletal trauma. This is slightly higher than the range reported by the National Nosocomial Infections Surveillance (NNIS) for orthopaedic patients [25], suggesting that, as expected by their injury process compared with the average orthopaedic surgical patients [7, 26, 34], those having surgery to treat skeletal trauma are at increased risk for a SSI [3, 14, 16, 32, 37, 42] (Table 8). Although there have been reports of general orthopaedic patients with SSI incidences of $4.8 \%$ [39], and $22.7 \%$ [20], these studies were performed in nations in which infection control practices may not be as optimal [20] as in developed nations. 


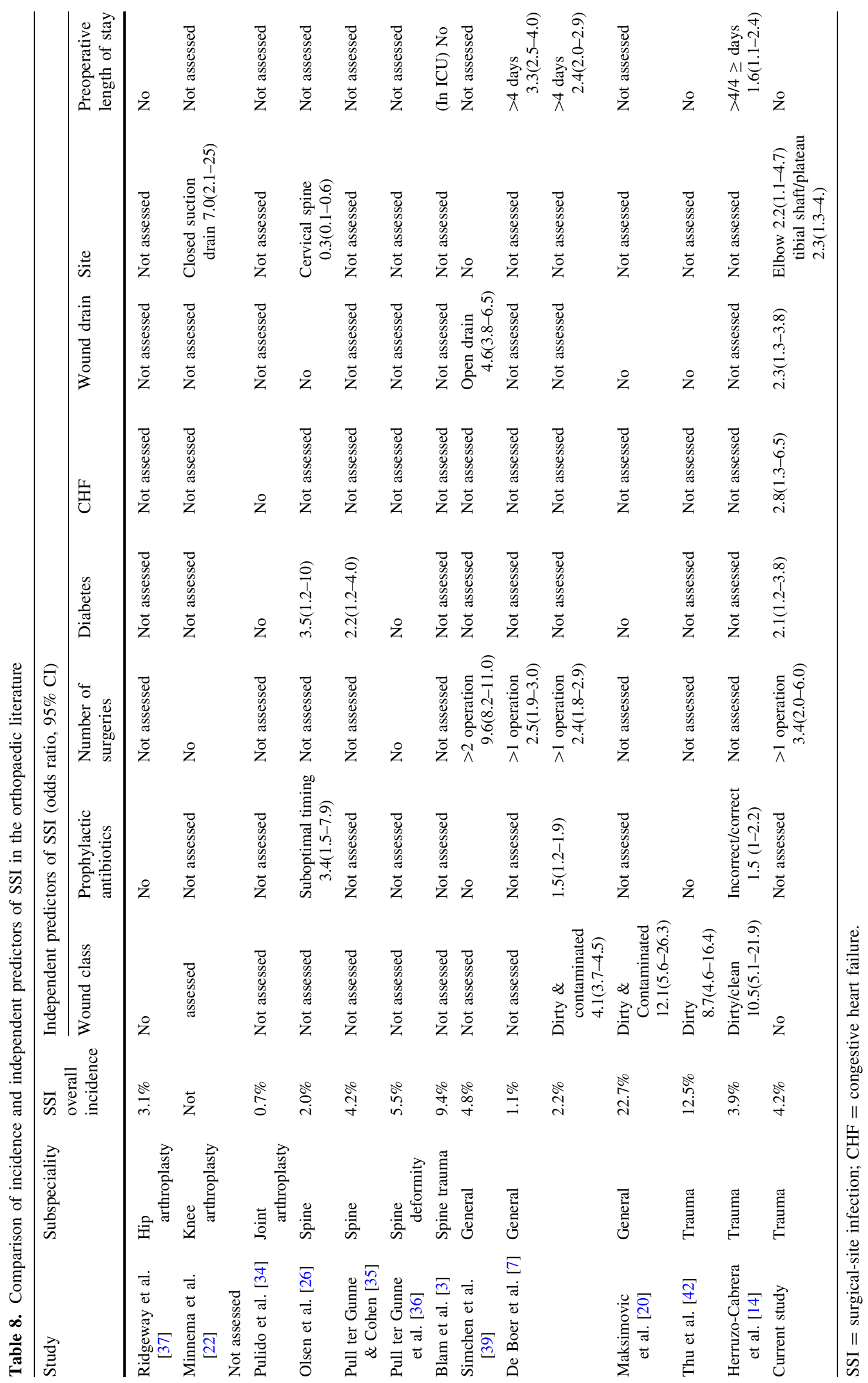


Our study confirmed some risk factors reported in other studies for SSIs, such as the use of a wound drain, ASA classification, CHF, number of operations, wound classification, diabetes, and the use of temporary external fixation $[2,6,7,29,30,33,38,39,41,46,47]$. One study of several types of general, orthopaedic, and gynecologic surgeries found low volume surgeons are a risk factor for development of a SSI [24]; however, specific surgeon was not a risk factor in our analysis of patients with orthopaedic trauma. It is possible that the effect of individual surgeon practices was dwarfed by stronger risk factors.

We found six independent predictors of SSIs (Table 4). Unlike other studies [7, 14], we did not find a long preoperative hospital stay to be associated with infection nor to independently predict SSI. The site of surgery (tibial shaft/plateau and elbow) independently predicted SSI (Table 8). The elbow may be at an increased risk for having infection develop owing to its subcutaneous locations and poor soft tissue coverage [23], but we also believe we had a problem with subcutaneous suture reactions and have changed the type of subcutaneous suture that we use. Heier et al. [13] also found that the trauma site and the degree of contamination increase the risk of a SSI. The fact that a wound drain was associated with an increased risk for SSI does not implicate the drain itself. Two randomized controlled trials in patients undergoing surgical fracture fixation or bone grafting showed a wound drain provided no benefit to rates of infection, hematomas, transfusion, or revision surgery [19, 43]. Wound drain use and multiple surgeries are likely surrogates for more complex injuries, particularly more complex wounds. Use of temporary external fixation is also likely an indicator of soft tissue injury or soft tissue problems, rather than an independent risk factor on the basis of colonized pin tracks or other factors, an argument supported by the fact that temporary external fixation was not included in the best multivariable model. The number of operations may be indicative of the complexity of the injury and may explain why the probabilities for infection almost double with multiple surgeries. The contribution of diabetes to SSI risk is inconsistent [21], perhaps owing to the incomplete accounting for confounding [8, 28, 38]. However, diabetes is a strong and consistent risk factor for SSI in spinal surgery [5, 10, 26, 35]. Diabetic status was identified using the medical history section of patients' medical records, but did not account for the level of glycemic control, as not all patients had an HbA1c drawn nor were glucose finger stick results readily available when reviewing the electronic medical record. Despite the crude binary classification, diabetes was a strong risk factor for infection after fracture surgery in this study. CHF was also a strong risk factor. This may be related to poor postoperative wound oxygenation. However, the degree and level of control of CHF were not assessed in this study as not all patients routinely had echocardiograms performed.

Patients with orthopaedic trauma are at an increased risk of having SSIs develop as compared with the general orthopaedic population. We found the use of a drain, number of operations, CHF, diabetes, and site of injury independently predicted SSI after operative fracture treatment. We believe that these risk factors reflect patient infirmity and injury complexity, rather than factors amenable to intervention.

Open Access This article is distributed under the terms of the Creative Commons Attribution Noncommercial License which permits any noncommercial use, distribution, and reproduction in any medium, provided the original author(s) and source are credited.

\section{References}

1. American Society of Anesthesiologists. ASA Physical Status Classification System. Available at http://www.asahq.org/clinical/ physicalstatus.htm. Accessed September 25, 2010.

2. Berbari EF, Hanssen AD, Duffy MC, Steckelberg JM, Ilstrup DM, Harmsen WS, Osmon DR. Risk factors for prosthetic joint infection: case-control study. Clin Infect Dis. 1998;27:12471254.

3. Blam OG, Vaccaro AR, Vanichkachorn JS, Albert TJ, Hilibrand AS, Minnich JM, Murphey SA. Risk factors for surgical site infection in the patient with spinal injury. Spine(Phila Pa 1976) 2003;28:1475-1480.

4. Centers for Disease Control and Prevention, National Center for Health Statistics. Vital and Health Statistics, Detailed Diagnoses and Procedures, National Hospital Discharge Survey 1994. Hyattsville, MD: Department of Health and Human Services; 1997.

5. Chen S, Anderson MV, Cheng WK, Wongworawat MD. Diabetes associated with increased surgical site infections in spinal arthrodesis. Clin Orthop Relat Res. 2009;467:1670-1673.

6. de Boer AS, Geubbels EL, Wille J, Mintjes-de Groot AJ. Risk assessment for surgical site infections following total hip and total knee prostheses. J Chemother. 2001;13:42-47.

7. de Boer AS, Mintjes-de Groot AJ, Severijnen AJ,van den Berg $\mathrm{JM}$, van Pelt W. Risk assessment for surgical-site infections in orthopedic patients. Infect Control Hosp Epidemiol. 1999;20: 402-407.

8. Enstone JE, Humphreys H. Monitoring infective complications following hip fracture. J Hosp Infect. 1998;38:1-9.

9. Garner JS. CDC guideline for prevention of surgical wound infections, 1985. Supersedes guideline for prevention of surgical wound infections published in 1982. (Originally published in November 1985). Revised. Infect Control. 1986;7:193-200.

10. Golden SH, Peart-Vigilance C, Kao WH, Brancati FL. Perioperative glycemic control and the risk of infectious complications in a cohort of adults with diabetes. Diabetes Care. 1999;22: 1408-1414

11. Haley RW, Culver DH, White JW, Morgan WM, Emori TG. The nationwide nosocomial infection rate: a new need for vital statistics. Am J Epidemiol. 1985;121:159-167.

12. Harrell FE Jr, Lee KL, Mark DB. Multivariable prognostic models: issues in developing models, evaluating assumptions and adequacy, and measuring and reducing errors. Stat Med. 1996;15: 361-387. 
13. Heier KA, Infante AF, Walling AK, Sanders RW. Open fractures of the calcaneus: soft-tissue injury determines outcome. $J$ Bone Joint Surg Am. 2003;85:2276-2282.

14. Herruzo-Cabrera R, López-Giménez R, Diez-Sebastian J, Lopez-Aciñero MJ, Banegas-Banegas JR. Surgical site infection of 7301 traumatologic inpatients (divided in two sub-cohorts, study and validation): modifiable determinants and potential benefit. Eur J Epidemiol. 2004;19:163-169.

15. Horan TC, Gaynes RP, Martone WJ, Jarvis WR, Emori TG. CDC definitions of nosocomial surgical site infections, 1992: a modification of CDC definitions of surgical wound infections. Infect Control Hosp Epidemiol. 1992;13:606-608.

16. Jarvis WR. Selected aspects of the socioeconomic impact of nosocomial infections: morbidity, mortality, cost, and prevention. Infect Control Hosp Epidemiol. 1996;17:552-557.

17. Jämsen E, Huhtala H, Puolakka T, Moilanen T. Risk factors for infection after knee arthroplasty: a register-based analysis of 43,149 cases. J Bone Joint Surg Am. 2009; 91:38-47.

18. Katz M. Multivariable Analysis: A Practical Guide for Clinicians. 2nd ed. Cambridge, MA: Cambridge University Press; 2006:96-116.

19. Lang GJ, Richardson M, Bosse MJ, Greene K, Meyer RA Jr, Sims SH, Kellam JF. Efficacy of surgical wound drainage in orthopaedic trauma patients: a randomized prospective trial. J Orthop Trauma. 1998;12:348-350.

20. Maksimovic J, Markovic-Denic L, Bumbasirevic M, Marinković J. [Incidence of surgical site infections in the departments of orthopedics and traumatology] [in Serbian]. Vojnosanit Pregl. 2006;63:725-729.

21. Mangram AJ, Horan TC, Pearson ML, Silver LC, Jarvis WR. Guideline for prevention of surgical site infection, 1999. Hospital Infection Control Practices Advisory Committee. Infect Control Hosp Epidemiol. 1999;20:250-278.

22. Minnema B, Vearncombe M, Augustin A, Gollish J, Simor AE. Risk factors for surgical-site infection following primary total knee arthroplasty. Infect Control Hosp Epidemiol. 2004;25: 477-480.

23. Morrey BF, Bryan RS. Complications of total elbow arthroplasty. Clin Orthop Relat Res. 1982;170:204-212.

24. Muilwijk J, van den Hof S, Wille JC. Associations between surgical site infection risk and hospital operation volume and surgeon operation volume among hospitals in the Dutch nosocomial infection surveillance network. Infect Control Hosp Epidemiol. 2007;28:557-563.

25. National Nosocomial Infections Surveillance System. National Nosocomial Infections Surveillance (NNIS) System Report, data summary from January 1992 through June 2004, issued October 2004. Am J Infect Control. 2004;32:470-485.

26. Olsen MA, Nepple JJ, Riew KD, Lenke LG, Bridwell KH, Mayfield J, Fraser VJ. Risk factors for surgical site infection following orthopaedic spinal operations. J Bone Joint Surg Am. 2008:90:62-69.

27. Owens WD, Felts JA, Spitznagel EL Jr. ASA physical study classifications: a study of consistency of ratings. Anesthesiology. 1978;49:239-243.

28. Partanen J, Syrjala H, Vahanikkila H, Jalovaara P. Impact of deep infection after hip fracture surgery on function and mortality. J Hosp Infect. 2006;62:44-49.

29. Peersman G, Laskin R, Davis J, Peterson M. Infection in total knee replacement: a retrospective review of 6489 total knee replacements. Clin Orthop Relat Res. 2001;392:15-23.
30. Phillips JE, Crane TP, Noy M, Elliott TS, Grimer RJ. The incidence of deep prosthetic infections in a specialist orthopaedic hospital: a 15-year prospective survey. J Bone Joint Surg Br. 2006;88:943-948.

31. Polk HC Jr, Simpson CJ, Simmons BP, Alexander JW. Guidelines for prevention of surgical wound infection. Arch Surg. 1983;118:1213-1217.

32. Pories SE, Gamelli RL, Mead PB, Goodwin G, Harris F, Vacek P. The epidemiologic features of nosocomial infections in patients with trauma. Arch Surg. 1991;126:97-99.

33. Poss R, Thornhill TS, Ewald FC, Thomas WH, Batte NJ, Sledge CB. Factors influencing the incidence and outcome of infection following total joint arthroplasty. Clin Orthop Relat Res. 1984; 182:117-126.

34. Pulido L, Ghanem E, Joshi A, Purtill JJ, Parvizi J. Periprosthetic joint infection: the incidence, timing, and predisposing factors. Clin Orthop Relat Res. 2008;466:1710-1715.

35. Pull ter Gunne AF, Cohen DB. Incidence, prevalence, and analysis of risk factors for surgical site infection following adult spinal surgery. Spine(Phila Pa 1976). 2009;34:1422-1428.

36. Pull ter Gunne AF, van Laarhoven CJ, Cohen DB. Incidence of surgical site infection following adult spinal deformity surgery: an analysis of patient risk. Eur Spine J. 2010;19:982-988.

37. Ridgeway S, Wilson J, Charlet A, Kafatos G, Pearson A, Coello R. Infection of the surgical site after arthroplasty of the hip. J Bone Joint Surg Br. 2005;87:844-850.

38. Saleh K, Olson M, Resig S, Bershadsky B, Kuskowski M, Gioe T, Robinson H, Schmidt R, McElfresh E. Predictors of wound infection in hip and knee joint replacement: results from a 20 year surveillance program. J Orthop Res. 2002;20:506-515.

39. Simchen E, Stein H, Sacks TG, Shapiro M, Michel J. Multivariate analysis of determinants of postoperative wound-infection in orthopaedic patients. J Hosp Infect. 1984;5:137-146.

40. Smyth ET, Emmerson AM. Surgical site infection surveillance. J Hosp Infect. 2000;45:173-184.

41. Surin VV, Sundholm K, Backman L. Infection after total hip replacement: with special reference to a discharge from the wound. J Bone Joint Surg Br. 1983;65:412-418.

42. Thu LT, Dibley MJ, Ewald B, Tien NP, Lam LD. Incidence of surgical site infections and accompanying risk factors in Vietnamese orthopaedic patients. J Hosp Infect. 2005;60:360367.

43. Tjeenk RM, Peeters MP, van den Ende E, Kastelein GW, Breslau PJ. Wound drainage versus non-drainage for proximal femoral fractures: a prospective randomised study. Injury. 2005;36:100-104.

44. Vittinghoff E, McCulloch CE. Relaxing the rule of ten events per variable in logistic and Cox regression. Am J Epidemiol. 2007; 165:710-718.

45. Whitehouse JD, Friedman ND, Kirkland KB, Richardson WJ, Sexton DJ. The impact of surgical site infections following orthopedic surgery at a community hospital and a university hospital: adverse quality of life, excess length of stay, and extra cost. Infect Control Hosp Epidemiol. 2002;23:183-189.

46. Wilson MG, Kelley K, Thornhill TS. Infection as a complication of total knee-replacement arthroplasty: risk factors and treatment in sixty-seven cases. J Bone Joint Surg Am. 1990;72: 878-883.

47. Yokoyama K, Uchino M, Nakamura K, Ohtsuka H, Suzuki T, Boku T, Itoman M. Risk factors for deep infection in secondary intramedullary nailing after external fixation for open tibial fractures. Injury. 2006;37:554-560. 